\title{
Transanal total mesorectal excision (TaTME) versus laparoscopic TME for MRI-defined low rectal cancer: a propensity score-matched analysis of oncological outcomes
}

\author{
Sapho Xenia Roodbeen ${ }^{1} \cdot$ Marta Penna $^{2} \cdot$ Hugh Mackenzie $^{4} \cdot$ Miranda Kusters $^{5}$. Andrew Slater ${ }^{3}$. Oliver M. Jones ${ }^{2}$. \\ lan Lindsey ${ }^{2} \cdot$ Richard J. Guy ${ }^{2} \cdot$ Chris Cunningham ${ }^{2} \cdot$ Roel Hompes $^{1}$
}

Received: 18 March 2018 / Accepted: 11 October 2018 / Published online: 22 October 2018

(c) The Author(s) 2018

\begin{abstract}
Background While a shift to minimally invasive techniques in rectal cancer surgery has occurred, non-inferiority of laparoscopy in terms of oncological outcomes has not been definitely demonstrated. Transanal total mesorectal excision (TaTME) has been pioneered to potentially overcome difficulties experienced when operating with a pure abdominal approach deep down in the pelvis. This study aimed to compare short-term oncological results of TaTME versus laparoscopic TME (lapTME), based on a strict anatomical definition for low rectal cancer on MRI.

Methods From June 2013, all consecutive TaTME cases were included and compared to lapTME in a single institution. Propensity score-matching was performed for nine relevant factors. Primary outcome was resection margin involvement (R1), secondary outcomes included intra- and post-operative outcomes.

Results After matching, forty-one patients were included in each group; no significant differences were observed in patient and tumor characteristics. The resection margin was involved in 5 cases $(12.2 \%)$ in the laparoscopic group, versus $2(4.9 \%)$ TaTME cases $(P=0.432)$. The TME specimen quality was complete in $84.0 \%$ of the laparoscopic cases and in $92.7 \%$ of the TaTME cases $(P=0.266)$. Median distance to the circumferential resection margin $(\mathrm{CRM})$ was $5 \mathrm{~mm}$ in lapTME and $10 \mathrm{~mm}$ in TaTME $(P=0.065)$. Significantly more conversions took place in the laparoscopic group, $9(22.0 \%)$ compared to none in the TaTME group $(P<0.001)$. Other clinical outcomes did not show any significant differences between the two groups. Conclusion This is the first study to compare results of TaTME with lapTME in a highly selected patient group with MRIdefined low rectal tumors. A significant decrease in R1 rate could not be demonstrated, although conversion rate was significantly lower in this TaTME cohort.
\end{abstract}

Keywords Rectal cancer · Transanal TME · Conversion · Laparoscopic TME · CRM · Minimal Invasive Surgery · MRI

Roel Hompes

roelhompes@gmail.com; r.hompes@amc.uva.nl

1 Department Surgery, Amsterdam University Medical Centers, University of Amsterdam, Meibergdreef 9, 1105 AZ Amsterdam, The Netherlands

2 Department of Colorectal Surgery, Churchill Hospital, Oxford University Hospital NHS Foundation Trust, Oxford, UK

3 Department of Radiology, Churchill Hospital, Oxford University Hospitals NHS Foundation Trust, Oxford, UK

4 Department of Surgery and Cancer, Imperial College London, London, UK

5 Department of Surgery, Catharina Hospital, Eindhoven, The Netherlands
Colorectal cancer remains the third most common malignancy worldwide [1]. The outcomes for patients with rectal cancer have improved since the widespread adoption of total mesorectal excision (TME) [2] and use of neo-adjuvant therapy. Achieving a good quality TME with negative margins is of paramount importance for an optimal oncological resection, reducing the risk of loco-regional recurrence and improving cancer-free survival $[3,4]$. Low rectal cancer, however, remains technically challenging. As the distance between the rectal wall and mesorectal fascia tapers towards the anus, the range for error reduces and thus it becomes more difficult to obtain clear margins. Other factors, such as a narrow, irradiated pelvis and obesity, also predict intra-operative difficulties [5]. Consequently, oncological outcomes of low rectal cancer remain inferior compared to 
more proximal tumors, with higher rates of resection margin involvement and local recurrences [6].

The impact of minimally invasive techniques is evident in regard to short-term peri-operative outcomes, but the effectiveness in terms of oncological results is still a matter of current debate [7-9]. In laparoscopic surgery, the visualization is often limited, particularly in the lower pelvis, due to fixed trocar positions with insufficient angulation in the rigid bony pelvis. This may lead to imprecise distal margin determination with a challenging distal transection, high conversion rates, up to $34 \%$ [10], and associated increased risk of loco-regional recurrence $[11,12]$.

Transanal TME (TaTME), also known as 'bottom up' TME, has been pioneered to overcome these difficulties. The approach from below offers clear, direct visualization of the dissection plane, even in a narrow pelvis, allowing a more precise and trauma-free dissection, which should improve the quality of the TME specimen and decrease positive resection margins.

A meta-analysis by $\mathrm{Xu}$ et al. showed that short-term outcomes from small cohort studies assessing the benefit of TaTME are promising [13]. However, most comparative studies include rectal tumors at all heights, and therefore potentially underestimate the real benefits of TaTME, as this approach is probably most valuable in lower tumors.

This is the first study to specifically compare TaTME with lapTME for MRI-defined low rectal cancers, according to the LOREC definition for low rectal cancer [14]. By using this definition, based on the anatomical landmark where the tapering of the mesorectum starts, this study focused on a patient group known to pose greater technical difficulty with increased risk of R1 resection (Fig. 1).

Our institution adopted and performed TaTME since 2013 as a new surgical approach to treat low rectal cancer. In this propensity score-matching analysis, we aimed to evaluate histopathological and peri-operative outcomes of TaTME versus conventional lapTME, specifically for MRI-defined low rectal cancers.

\section{Methods}

\section{Study design and patient selection}

A single-center prospective cohort study was conducted, comparing TaTME with lapTME. From the first case in June 2013 until July 2017, all rectal cancer patients undergoing TaTME in Oxford were analyzed. All TaTME cases performed in the unit were recorded on the international TaTME registry [15], a prospectively kept database, following the national NICE guidelines. Data were extracted from this database. The control cohort consisted of all rectal cancer cases operated on between August 2006 to July 2017; their data were collected on a prospective institutional database, and cases were further reviewed retrospectively collecting any additional information required for the study.

All patients had biopsy proven rectal adenocarcinoma and underwent curative TME surgery. Benign cases, squamous cancers, beyond TME resections (extra-visceral), recurrent cancer, and patients with previous local excision were excluded. Subsequently, all staging MRI scans were reviewed by $\mathrm{RH}, \mathrm{SR}$ and an expert radiologist (AS), in order to only include patients with MRI defined low rectal tumors. In accordance with the LOREC [14] definition of low rectal cancer, a tumor was considered low if the distal border was located distal to the point where the levator ani muscles insert on the pelvic bone on sagittal MRI (Fig. 1).

In an attempt to reduce bias of confounding factors in this observational study, the two groups were matched for nine variables using propensity scores with a tolerance of 0.01 ,
Fig. 1 MRI definition of a low rectal tumor (sagittal (left) and coronal (right) T2 MRI-scans showing the line between the pubic bone and the origin of the levator muscles: a tumor below this line was defined as a low rectal cancer)
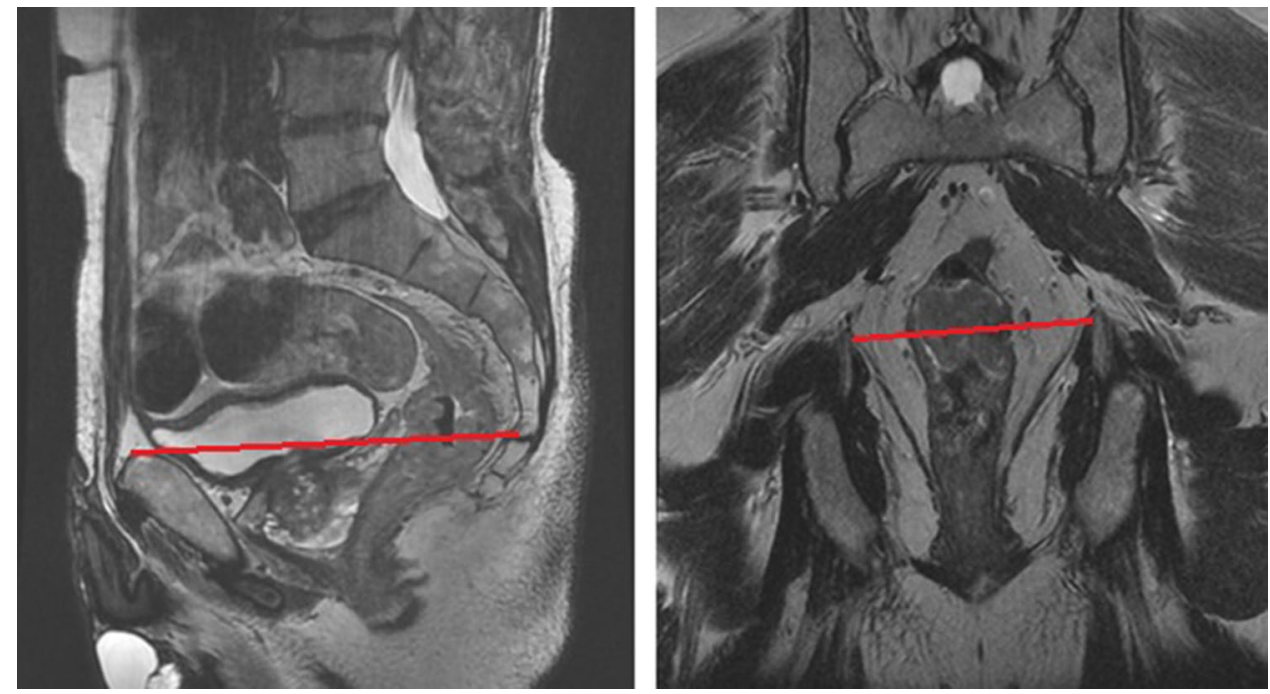
on a one-to-one basis. Independent variables included in the model were sex, age ( $<65$ or $>65$ years), ASA $(1-2$ or $3-4)$, BMI ( $<30$ or $>30$ in $\left.\mathrm{kg} / \mathrm{m}^{2}\right)$, tumor height from anorectal junction $(0-1 \mathrm{~cm}$ or $>1 \mathrm{~cm})$, clinical TNM-stage (1-2 or $3-4$ ), neo-adjuvant therapy and type of operation (abdominoperineal excision (APE) or anterior resection (AR)). In the unmatched cohort, BMI was not known in five cases and therefore the mean BMI was imputed before matching. The matching was performed using propensity scores derived from a logistic regression model; the dependent variable was operative approach (TaTME or lapTME).

\section{Outcomes}

Primary outcome was resection margin involvement (R1 resection), defined as positive circumferential resection margin (CRM) and/or positive distal resection margin (DRM). Secondary outcomes included further histopathological features (specimen quality, length of circumferential and distal resection margins) and intra- and post-operative outcomes (conversion rate, intra-operative adverse events, 30-day morbidity including anastomotic leakage (AL), 30-day Clavien-Dindo, 30-day readmission rate).

Histopathological assessment of the specimen was carried out by experienced consultant histopathologists. A resection margin was considered involved if the distance of tumor or malignant lymph node to the edge of resection was $1 \mathrm{~mm}$ or less. Quality of the TME specimens was categorized using descriptions by Quirke et al. [16].

\section{Peri-operative course}

Preoperative assessment for rectal tumors included colonoscopy with biopsies, MR imaging of the pelvis and CT-scan of the chest, abdomen and pelvis. A multidisciplinary team decided whether patients needed neoadjuvant therapy, usually in the form of long course chemo-radiation. In these cases, a repeat MRI-scan was obtained to assess tumor regression after the neo-adjuvant therapy. All patients were treated according to the UK guidelines for the treatment of rectal cancer [17].

Pre-operatively, patients received mechanical bowel preparation and antibiotic prophylaxis was administered intravenously on the day of surgery. All procedures were performed by the same surgical team consisting of six colorectal surgeons in one hospital. Three of those surgeons started performing TaTME since 2013.

The TaTME technique is thoroughly described in a previously published article by our unit [18]. Transanal conversion was defined as a resection that was not completed transanally as intended, but rather continued further from the abdominal approach; either open, laparoscopic or robotic.
Laparoscopic TME was performed using a multi-port set-up, with completion of TME dissection laparoscopically from above. Conversion was defined as a procedure that was started with the intention to perform a laparoscopic dissection, but was completed as an open resection requiring a midline laparotomy. Decision of fashioning a diverting stoma was made for each patient individually.

Post-operatively, patients followed the enhanced-recovery protocol, introduced in 2015, when appropriate.

\section{Statistical analysis}

All categorical data are presented as number of cases and percentages, whilst continuous data are shown as either mean \pm standard deviation (range) or as median and interquartile range (IQR), depending on the data distribution. Data were analyzed using the Statistical Package for Social Sciences (SPSS) of IBM Statistics, version 24.0. Propensity score-matching was carried out as described above. Categorical and continuous variables were compared using a Chi-square test and the Mann-Whitney $U$ test, respectively. A Fisher's exact test was used for variables with less than five observations. A $P$ value $\leq 0.05$ was considered statistically significant.

\section{Results}

A total of 81 consecutive patients underwent TaTME in the period June 2013 until July 2017, of whom 52 patients met the inclusion criteria. The conventional group consisted of 127 patients with low rectal cancer who underwent laparoscopic TME surgery between August 2006 to December 2016. After propensity score-matching, 41 patients in each group were included for comparison. Patient and tumor characteristics are shown in Table 1, no significant differences were observed between the two groups.

In both groups, the majority was male, $32(78.1 \%)$ in the laparoscopic group and 34 (82.9\%) in the TaTME group $(P=0.577)$. Median tumor height from anorectal junction was $1.5 \mathrm{~cm}$ (IQR 0.0-3.0) in the lapTME group and $2.0 \mathrm{~cm}$ (IQR 0.0-4.0) in the TaTME group $(P=0.489)$. On pre-operative MRI, the tumor was located anteriorly in 19 patients (46.3\%) in the laparoscopic group versus 24 patients (58.5\%) in the TaTME group $(P=0.447)$. The CRM was threatened in 19 patients in both groups.

Histopathological outcomes are depicted in Table 2. Resection margin (R1) was positive in 5 cases (12.2\%) in the lapTME group versus $2(4.9 \%)$ positive margins, both due to positive CRM, in the TaTME group $(P=0.432)$. In the lap TME group, the resection margin was involved due to a positive CRM in two specimens, a positive DRM in two specimens, and in one specimen, both the CRM and DRM 
Table 1 Patient and tumor characteristics

\begin{tabular}{|c|c|c|c|}
\hline Factor & $\begin{array}{l}\text { Laparoscopic TME } \\
41 \text { cases }\end{array}$ & $\begin{array}{l}\text { TaTME } \\
41 \text { cases }\end{array}$ & $P$ value \\
\hline \multicolumn{4}{|l|}{ Patient characteristics } \\
\hline \multicolumn{4}{|l|}{ Gender, $n(\%)$} \\
\hline Male & $32(78.0)$ & $34(82.9)$ & 0.577 \\
\hline Female & $9(22.0)$ & $7(17.1)$ & \\
\hline Age in years, mean $\pm \mathrm{SD}$ (range) & $66.0 \pm 9.2(48-83)$ & $62.5 \pm 10.7(33-87)$ & 0.145 \\
\hline \multicolumn{4}{|l|}{ ASA score, $n(\%)$} \\
\hline $\mathrm{I}+\mathrm{II}$ & $38(92.7)$ & $36(87.8)$ & 0.523 \\
\hline $\mathrm{III}+\mathrm{IV}$ & $3(7.3)$ & $5(12.2)$ & \\
\hline $\mathrm{BMI}$ in $\mathrm{kg} / \mathrm{m}^{2}$, mean $\pm \mathrm{SD}$ (range) & $26.1 \pm 4.0(19.4-36.0)$ & $26.7 \pm 1.9(20.9-32.3)$ & 0.243 \\
\hline \multicolumn{4}{|l|}{ Neoadjuvant therapy, $n(\%)$} \\
\hline No & $23(56.1)$ & $23(56.1)$ & 0.086 \\
\hline RT & $5(12.2)$ & $0(0.0)$ & \\
\hline Chemo & $0(0.0)$ & $1(2.4)$ & \\
\hline CRT & $13(31.7)$ & $15(36.6)$ & \\
\hline SCRT & $0(0.0)$ & $2(4.9)$ & \\
\hline \multicolumn{4}{|l|}{ Tumor characteristics on MRI } \\
\hline Height from ARJ in cm, median (IQR) & $1.5(0.0-3.0)$ & $2.0(0.0-4.0)$ & 0.489 \\
\hline Tumor size in mm, median (IQR) & $43.0(37.0-55.0)$ & $46.5(34.5-53.8)$ & 0.890 \\
\hline Anteriorly located, $n(\%)$ & $19(46.3)$ & $24(58.5)$ & 0.447 \\
\hline \multicolumn{4}{|l|}{ TNM-staging, $n(\%)$} \\
\hline Stage 1 & $8(19.5)$ & $9(22.0)$ & 1.000 \\
\hline Stage 2 & $16(39.0)$ & $15(36.6)$ & \\
\hline Stage 3 & $13(31.7)$ & $13(31.7)$ & \\
\hline Stage 4 & $4(9.8)$ & $4(9.8)$ & \\
\hline CRM involvement, $n(\%)$ & $19 / 39(48.7)$ & $19 / 41(46.3)$ & 0.832 \\
\hline
\end{tabular}

CRM involvement on MRI is defined as involved if the distance of tumor or malignant lymph node to the mesorectal fascia was $\leq 1 \mathrm{~mm}$ on MRI

Percentages are shown as percentages of the whole group not including missing values

$S D$ standard deviation, $I Q R$ inter quartile range, ASA American Society of Anaesthesiologists, BMI Body Mass Index, $A R J$ anorectal junction were involved. The quality of the specimen was graded as complete in $84.0 \%$ in the laparoscopic group versus $92.7 \%$ in the TaTME group $(P=0.412)$. Median tumor distance to the CRM in the lapTME group was $5 \mathrm{~mm}$ (IQR 3.0-10.0) versus $10 \mathrm{~mm}$ (IQR 4.2-12.0) after TaTME $(P=0.065)$. The mean number of harvested lymph nodes was 14 (IQR 11-24) in the lapTME versus 18 (IQR 13-26) in the TaTME group $(P=0.102)$.

Table 3 presents clinical outcomes. Conversion rate to midline was significantly lower in the TaTME group, namely $0(0.0 \%)$, against $9(22.0 \%)$ conversions in the lapTME group $(P<0.001)$. Median operative time was $300 \mathrm{~min}$ (IQR 240-378) in the laparoscopic group and $318 \mathrm{~min}$ (IQR 270-375) in the TaTME group $(P=0.290)$. AL rate did not differ significantly and was $14.8 \%$ in lapTME and $17.9 \%$ in TaTME $(P=1.000)$. All anastomotic leakages occurred within 30 days after index surgery. Hospital stay was 8 days (IQR 7-11) in the TaTME group and 11 days (IQR 8-17) after lapTME $(P=0.052)$. In all TaTME cases, a defunctioning stoma was fashioned. Thirty-day unplanned readmission rate and Clavien-Dindo classification scores did not show any significant differences between the two groups. In the lapTME group, five patients developed a Clavien-Dindo IIIb complication, of which three cases were anastomosis related. In the TaTME group, four of the six patients with a Clavien-Dindo IIIb complication had anastomosis-related problems.

\section{Discussion}

This propensity score-matching analysis is the first study that compares TaTME with lapTME for low rectal cancer based on a strict anatomical definition. By including only MRI-defined low rectal cancers, we have focused on a highly selected patient group, known to pose greater technical difficulty and increased risk of poorer oncological and clinical 
Table 2 Histopathological outcomes

\begin{tabular}{|c|c|c|c|}
\hline Factor & $\begin{array}{l}\text { Laparoscopic TME } \\
41 \text { cases }\end{array}$ & $\begin{array}{l}\text { TaTME } \\
41 \text { cases }\end{array}$ & $P$ value \\
\hline \multicolumn{4}{|l|}{ Primary outcome } \\
\hline $\mathrm{R} 1$ resection, $n(\%)$ & $5(12.2)$ & $2(4.9)$ & 0.432 \\
\hline Positive CRM & $3^{(1 \mathrm{AR}, 2 \mathrm{APE})}$ & $2^{(2 \mathrm{AR})}$ & 0.675 \\
\hline Positive DRM & $3^{(3 \mathrm{AR})}$ & 0 & 0.241 \\
\hline \multicolumn{4}{|l|}{ Secondary histological outcomes } \\
\hline Tumor distance to CRM in mm, median (range) & $5.0(3.0-10.0)$ & $10.0(4.2-12.0)$ & 0.065 \\
\hline Tumor distance to DRM in mm, median (range) & $20.0(9.8-41.3)$ & $20.0(10.0-40.0)$ & 0.649 \\
\hline \multicolumn{4}{|l|}{ Pathological T stage, $n(\%)$} \\
\hline урТ0 & $2(4.9)$ & $2(4.9)$ & 0.809 \\
\hline $\mathrm{T} 1$ & $3(7.3)$ & $1(2.4)$ & \\
\hline $\mathrm{T} 2$ & $11(26.8)$ & $13(31.7)$ & \\
\hline $\mathrm{T} 3$ & $25(61.0)$ & $25(61.0)$ & \\
\hline $\mathrm{T} 4$ & $0(0.0)$ & $0(0.0)$ & \\
\hline \multicolumn{4}{|l|}{ Pathological N stage, $n(\%)$} \\
\hline No & $22(53.7)$ & $26(63.4)$ & 0.679 \\
\hline N1 & $15(36.6)$ & $11(26.8)$ & \\
\hline $\mathrm{N} 2$ & $4(9.8)$ & $4(9.8)$ & \\
\hline \multicolumn{4}{|l|}{ Specimen quality, $n(\%)$} \\
\hline Complete & $21(84.0)$ & $38(92.7)$ & 0.412 \\
\hline Minor defects & $4(16.0)$ & $3(7.3)$ & \\
\hline Major defects & $0(0.0)$ & $0(0.0)$ & \\
\hline Missing & 16 & 0 & \\
\hline Lymph nodes harvested, median (range) & $14(11-24)$ & $18(13-26)$ & 0.102 \\
\hline
\end{tabular}

Table 3 Clinical outcomes

\begin{tabular}{lcrr}
\hline Factor & $\begin{array}{l}\text { Laparoscopic TME } \\
41 \text { cases }\end{array}$ & $\begin{array}{l}\text { TaTME } \\
41 \text { cases }\end{array}$ & $P$ value \\
\hline Operative time minutes, median (range) & $300(240-378)$ & $318(270-375)$ & 0.290 \\
Operation type, $n(\%)$ & & & \\
AR & $27(65.9)$ & $28(68.3)$ & 0.814 \\
APE & $14(34.1)$ & $13(31.7)$ & \\
Intra-operative complications, $n(\%)$ & $3(7.3)$ & $1(2.4)$ & 0.616 \\
Conversion (to midline), $n(\%)$ & $9(22.0)$ & $0(0.0)$ & $<\mathbf{0 . 0 0 1}$ \\
Defunctioning stoma, $n(\%)$ & $24 / 27(88.9)$ & $28 / 28(100.0)$ & 0.070 \\
Hospital stay in days, median (range) & $11(8-17)$ & $8(7-11)$ & 0.052 \\
Unplanned Readmissions within 30 days, $n(\%)$ & $8(19.5)$ & $6(14.6)$ & 0.557 \\
Postoperative complications within 30 days, $n(\%)$ & $14(34.1)$ & $19(46.3)$ & 0.260 \\
Anastomotic leakage, $n(\%)$ & $4 / 27(14.8)$ & $5 / 28(17.9)$ & 1.000 \\
Clavien-Dindo 30 days classification, $n(\%)$ & & & \\
None & $27(65.9)$ & $22(53.7)$ & 0.772 \\
I & $3(7.3)$ & $6(14.6)$ & \\
II & $4(9.8)$ & $4(9.8)$ & \\
IIIa & $2(4.9)$ & $3(7.3)$ & \\
IIIb & $5(12.2)$ & $6(14.6)$ & \\
IV and V & $0(0.0)$ & $0(0.0)$ & \\
\hline
\end{tabular}

Intra-operative complications defined as major complications, including: visceral injury, bleeding, ischaemia. Not including conversion 
outcomes. Moreover, by propensity matching for nine potential confounding factors, homogeneous groups for comparison were created.

This study did not show a significant decrease in R1 resections after TaTME.

However, we were able to demonstrate a significant decrease in conversion rate from $22.0 \%$ in the laparoscopic group, to no converted cases in the TaTME cohort $(P<0.001)$. So far, six other comparative matched studies on this topic have been published [19-24], and only the study by Chen and Persiani [20,24] included more TaTME cases ( $n=50$ and $n=46$, respectively). However, none of these studies focused specifically on low rectal cancer. Similarly to our findings, Persiani et al. also reported a significant decrease in conversion rates in TaTME versus lapTME, from 19.6 to $0 \%$, respectively. Low conversion rates for TaTME were also reported in the recent update from the International TaTME registry (4.3\%) and the largest systematic review to date by Deijen et al. (3\%) [25, 26]. The study by Oostendorp et al. [27] confirmed the promising conversion rates in TaTME, as the authors report on a conversion rate of $2 \%$ compared to $13.7 \%$ in a comparative cohort of four recent large RCT's on lapTME [7-9, 28]. The conversion rate in our comparative laparoscopic cohort was $22 \%$, which is comparable to other studies describing high conversion rates in laparoscopic TME, ranging from 12 to $50 \%$ [29-31]. The low conversion rates observed in TaTME have the potential to improve oncological outcomes, as several studies found increased risk of loco-regional recurrences and decreased disease-free survival rates in patients after converted laparoscopic procedures [11, 12]. Moreover, decreasing the conversion rate in TaTME also influences the longterm morbidity with a lower rate of incisional hernias and adhesional obstructions [32].

The hypothesis that TaTME improves positive margin rates was not confirmed in this study, although there appeared to be a trend towards lower R1 rates (from 12.2 to 4.9\%). The studies by Chen, De'Angelis, Marks and Velthuis et al. [21-24] showed a similar trend in decreased rate of positive margins after TaTME, although also not significant. The only comparative study reporting on a significant decrease in involved margins was the study by Chang and coworkers [19]; 0 of 23 cases in TaTME versus 4 of 23 cases after lapTME $(P=0.037)$. The reported positive resection margin rates in the first two reports from the international TaTME registry based on 634 and 1540 TME resections for cancer, were $2.7 \%$ and $4.9 \%$, respectively [25, 33]. The systematic review by Deijen et al. [26] analyzing 794 cases from 33 studies, reported a positive margin rate of $4.7 \%$. These results suggest that TaTME has the potential to decrease R1 rate, an important predictor of LR [34], when compared to lapTME, as three recent randomized controlled trials found R1 rates in laparoscopic TME surgery varying from 7 to $12 \%$ [7-9].

In this study, we matched for nine factors that are known to increase case difficulty and subsequently influence the risk of R1 resection. The Mercury II study group recently published a stratification model of pre-operative features on MRI that influence development of local recurrence after resection for rectal cancer [35]. Those risk factors on MRI are extra-mural vascular invasion (EMVI) status, an anteriorly located tumor, predicted CRM involvement and tumor height $<4 \mathrm{~cm}$ from anal verge. Correspondingly, we matched for tumor height $<1 \mathrm{~cm}$ from the anorectal junction. We were not able to match for the other factors; however, our baseline characteristics show that these variables were comparable between both groups, except for EMVI status, which was not routinely reported for all patients early on in the control group.

Over the past decades, surgical management for rectal cancer has changed. Nevertheless, whether by open or laparoscopic surgery, TME for low tumors encounters many challenges, which can be potentially overcome with TaTME. When approaching from below, patient characteristics seem to have less impact on the procedure, as a multivariate analysis in the study by Penna et al. [33], failed to show any patient characteristics to be of influence on the risk of poor specimen outcome in TaTME. Also, a clearer visualization may result in less traction on the specimen and more accurate TME dissection, possibly providing better quality TME and negative margins, a more accurate distal transection, and lower conversion rates compared to laparoscopic surgery. Furthermore, the technique allows for a double pursestring anastomosis, avoiding difficulties with stapling the rectal stump, and therefore may have the added potential to lower the anastomotic leak rate $[36,37]$.

This hypothesis on AL was not seen in our results. The AL rate of $18 \%$ in our TaTME cohort might seem relatively high. However, when interpreting these rates, tumor height must be taken into account. A large study by Borstlap et al. [38] found an early AL rate of $13.4 \%$ in patients who underwent low anterior resection, but this increased to $20 \%$ beyond 30 days. An independent risk factor for AL was a distal tumor ( $\leq 3 \mathrm{~cm}$ from ARJ), with an odds ratio of 1.88. The study by Bertelsen and coworkers [39] published on a five to six time increase in AL risk for low rectal tumors. The recent registry study on anastomotic leaks in TaTME by Penna et al. [25] published on an early AL rate of $7.8 \%$, which is within an acceptable range compared to previously reported incidences in colorectal surgery [40].

The learning curve effect regarding the new TaTME approach could be the reason why more significant differences were not seen favoring TaTME, in particular for histopathological outcomes and anastomotic leakage, but will hopefully 
improve with increasing surgeon experience. TaTME is not an easy surgical technique, and surgeons have to adapt to the unfamiliar anatomical view from below. Our institution regularly receives visitors and is a training center for surgeons aiming to learn TaTME. This might be the reason that operative time was not decreased in the TaTME group, while other comparative studies [22, 41-43] have reported on the ability of TaTME to effectively decrease operative time when performed with a two-team approach.

We acknowledge that this study has limitations. First, the retrospective view on prospectively collected data. By propensity score-matching for nine factors known to make a procedure more difficult, we attempted to create two comparable groups; nevertheless, we could not match for unknown confounders. Further, a large confounder in this study is time, as the inclusion period for the conventional cohort starts in 2006. This may have negatively influenced the outcomes of this group, as surgeons were still on their learning curve for laparoscopic TME, particularly in the early part of this period. However, we compared results to TaTME from the start of implementing this technique in our institution, and so included the early stages of the surgeons learning curve for both procedures. We could not account for possible other improvements in management over time, which might have skewed results. Third, the sample size is relatively small, resulting in a lack of statistical power. Finally, this study only reports on short-term outcomes. Currently, the literature on TaTME still lacks longterm oncological and functional data. Longer follow-up, on large patient cohorts, is needed to provide such data, hence the importance of the international TaTME registry [14]. Recently, an international randomized clinical trial (COLOR III [44]) comparing transanal to laparoscopic TME for rectal cancers started patient recruitment and will be completed in the next 5 to 8 years. While awaiting these results, non-randomized comparative studies are the best level of evidence available.

This study aimed to compare results of TaTME with lapTME in a highly selected patient group by only including MRI-defined low rectal tumors. No significant difference was found in R1 rate. This novel technique warrants further experience and prospective randomized studies to ensure oncologic safety and assess long-term functional results.

Funding We state that no funding was needed for this study.

\section{Compliance with ethical standards}

Disclosures Sapho Roodbeen, Marta Penna, Hugh Mackenzie, Miranda Kusters, Andrew Slater, Oliver Jones, Ian Lindsey, Richard J. Guy, Chris Cunningham, and Roel Hompes have no conflicts of interest or financial ties to disclose.

Open Access This article is distributed under the terms of the Creative Commons Attribution 4.0 International License (http://creat ivecommons.org/licenses/by/4.0/), which permits unrestricted use, distribution, and reproduction in any medium, provided you give appropriate credit to the original author(s) and the source, provide a link to the Creative Commons license, and indicate if changes were made.

\section{Appendix}

Abbreviations and definitions.

\begin{tabular}{|c|c|}
\hline TaTME & $\begin{array}{l}\text { Transanal total mesorectal exci- } \\
\text { sion }\end{array}$ \\
\hline APE & Abdominoperineal extirpation \\
\hline $\mathrm{AR}$ & Anterior resection \\
\hline R1 & $\begin{array}{l}\text { Microscopic presence of tumor } \\
\text { cells at the distal or circumferen- } \\
\text { tial resection margins or within } \\
\text { a lymph node }<1 \mathrm{~mm} \text { from the } \\
\text { mesorectal fascia of the excised } \\
\text { specimen }\end{array}$ \\
\hline $\mathrm{CRM}[+]$ & $\begin{array}{l}\text { Circumferential resection margin } \\
\text { of the excised specimen [pres- } \\
\text { ence of tumor cells within } 1 \mathrm{~mm} \\
\text { from the excised non-peritoneal- } \\
\text { ised surface of the rectum] }\end{array}$ \\
\hline $\operatorname{DRM}[+]$ & $\begin{array}{l}\text { Distal resection margin of the } \\
\text { excised specimen [presence of } \\
\text { tumor cells within } 1 \mathrm{~mm} \text { from } \\
\text { the excised distal end of the } \\
\text { specimen] }\end{array}$ \\
\hline Quality of TME specimen & $\begin{array}{l}\text { Using the Quirke grading system } \\
\text { for completeness of mesorectal } \\
\text { dissection, each TME speci- } \\
\text { men is graded as having either } \\
\text { an intact mesorectum, minor or } \\
\text { major defects. }{ }^{17}\end{array}$ \\
\hline TNM-stage & $\begin{array}{l}\text { Classification of colorectal } \\
\text { carcinoma (tumor, lymph nodes, } \\
\text { metastasis) }\end{array}$ \\
\hline ARJ & $\begin{array}{l}\text { Anorectal junction (located } \\
\text { approximately } 3 \mathrm{~cm} \text { proximal } \\
\text { from } \mathrm{AV} \text { ) }\end{array}$ \\
\hline AV & Anal valve \\
\hline EMVI & $\begin{array}{r}\text { Extra-mural vascular invasion } \\
\text { (sign seen on MRI-imaging) }\end{array}$ \\
\hline Clavien-Dindo classification & $\begin{array}{l}\text { Ranking classification of postop- } \\
\text { erative complications, based on } \\
\text { the therapy used for that specific } \\
\text { complication }\end{array}$ \\
\hline
\end{tabular}




\begin{tabular}{cc}
\hline 1 & Any deviation from the normal \\
postoperative course without the \\
need for pharmacological treat- \\
ment or surgical, endoscopic and \\
radiological interventions \\
Requiring pharmacological treat- \\
ment with drugs other than such \\
allowed for grade I complica- \\
tions \\
Requiring surgical, endoscopic \\
or radiological intervention not \\
under general anesthesia \\
Ra \\
Requiring surgical, endoscopic or \\
radiological intervention under \\
general anesthesia \\
Life-threatening complication \\
requiring IC/ICU-management \\
Death of a patient
\end{tabular}

Source http://www.assessurgery.com/clavien-dindo-classification/

\section{References}

1. Colorectal cancer statistics/World Cancer Research Fund International. http://www.wcrf.org/int/cancer-facts-figures/data-speci fic-cancers/colorectal-cancer-statistics. Accessed 11 Sep 2017

2. Heald RJ, Moran BJ, Ryall RD, Sexton R, MacFarlane JK (1998) Rectal cancer: the Basingstoke experience of total mesorectal excision, 1978-1997. Arch Surg 133:894-899

3. Quirke P, Steele R, Monson J, Grieve R, Khanna S, Couture J, O'Callaghan C, Myint AS, Bessel E, Thompson LC, Parmar M, Stephens RJ, Sebag-Montefiore D, Trial investigators MRC, NCRI Colorectal Cancer Study Group (2009) Effect of the plane of surgery achieved on local recurrence in patients with operable rectal cancer: a prospective study using data from the MRC CR07 and NCIC-CTG CO16 randomised clinical trial. Lancet 373:821-828

4. Martling A, Singnomklao T, Holm T, Rutqvist LE, Cedermark B (2004) Prognostic significance of both surgical and pathological assessment of curative resection for rectal cancer. Br J Surg 91:1040-1045

5. Cecil TD, Taffinder N, Gudgeon AM (2006) A personal view on laparoscopic rectal cancer surgery. Colorectal Dis 8:30-32

6. Nagtegaal ID, van de Velde CJH, Marijnen CAM, Krieken JHJM, Quirke P (2005) Low rectal cancer: a call for a change of approach in abdominoperineal resection. J Clin Oncol 23:9257-9264

7. Fleshman J, Branda M, Sargent DJ, Boller AM, Abbas VM, Peters WR, Maun D, Chang G, Herline A, Fichera A, Mutch M, Wexner S, Whiteford M, Marks J, Birnbaum E, Margolin D, larson D, Marcello P, Posner M, Read T, Monson J, Wren SM, Pisters PW, Nelson H (2015) Effect of laparoscopic-assisted resection vs open resection of stage II or III rectal cancer on pathologic outcomes: the ACOSOG Z6051 randomized clinical trial. JAMA 314:1346-1355

8. Stevenson AR, Solomon MJ, Lumley JW, Hewett P, Clouston AD, Gebski VJ, Davies L, Wilson K, Hague W, Simes J, ALaCaRT Investigators (2015) Effect of laparoscopic-assisted resection vs open resection on pathological outcomes in rectal cancer: the ALaCaRT randomized clinical trial. JAMA 314:1356-1363

9. van der Pas MH, Haglind E, Cuesta MA, Furst A, Lacy AM, Hop WC, Bonjer HJ, COLOR II Study Group (2013) Laparoscopic versus open surgery for rectal cancer (COLOR II): short-term outcomes of a randomised, phase 3 trial. Lancet Oncol 14:210-218

10. Guillou PJ, Quirke P, Thorpe H, Walker J, Jayne DG, Smith AM, Heath RM, Brown JM, MRC CLASSIC trial group (2005) Shortterm endpoints of conventional versus laparoscopic-assisted surgery in patients with colorectal cancer (MRC CLASICC trial): multicentre, randomised controlled trial. Lancet 365:1718-1726

11. Ptok H, Kube R, Schmidt U, Kockerling F, Gatsinger I, Lippert H, Colon/Rectum Carcinoma Study Group (2009) Conversion from laparoscopic to open colonic cancer resection-associated factors and their influence on long-term oncological outcome. Eur J Surg Oncol, 35:1273-1279

12. Chan AC, Fan JKM, Hung ÆS, Wai L, Law L (2008) Impact of conversion on the long-term outcome in laparoscopic resection of colorectal cancer. Surg Endosc 22:2625-2630

13. Xu W, Xu Z, Cheng H, Ying J, Cheng F, Xu W, Cao J, Luo J (2016) Comparison of short-term clinical outcomes between transanal and laparoscopic total mesorectal excision for the treatment of mid and low rectal cancer: a meta-analysis. Eur J Surg Oncol 42:1841-1850

14. Moran BJ, Holm T, Brannagan G, Chave H, Quirke P, West N, Brown G, Glynne-Jones R, Sebag-Montefiore D, Cunningham C, Janjua AZ, Battersby NJ, Crane S, McMeeking A (2014) The English national low rectal cancer development programme: key messages and future perspectives. Colorectal Dis 16:173-178

15. TaTME International Registry. https://tatme.medicaldata.eu/Defau 1t.aspx. Accessed: 03 July 2018

16. Quirke P, Durdey P, Dixon MF, Williams NS (1986) Local recurrence of rectal adenocarcinoma due to inadequate surgical resection. Histopathological study of lateral tumour spread and surgical excision. Lancet 2:996-999

17. Guidance and guidelinesINICE (2011) Colorectal cancer: diagnosis and management. https://www.nice.org.uk/guidance/cg131 . Accessed 28 Oct 2017

18. Buchs NC, Wynn G, Austin R, Penna M, Findlay JM, Bloemendaal AL, Mortensen NJ, Cunningham C, Jones OM, Guy RJ, Hompes R (2016) A two-centre experience of transanal total mesorectal excision. Colorectal Dis 18:1154-1161

19. Chang T-C, Kiu K-T (2017) Transanal total mesorectal excision in lower rectal cancer: comparison of short-term outcomes with conventional laparoscopic total mesorectal excision. J Laparoendosc Adv Surg Tech 28:365-369

20. Persiani R, Biondi A, Pennestri F, Fico V, De Simone V, Tirelli F, Santullo F, D’Uggo D (2018) Transanal total mesorectal excision vs laparoscopic total mesorectal excision in the treatment of low and middle rectal cancer: a propensity score matching analysis. Dis Colon Rectum 61:809-816

21. Marks JH, Montenegro GA, Salem JF, Shields MV, Marks GJ (2016) Transanal TATA/TME: a case-matched study of taTME versus laparoscopic TME surgery for rectal cancer. Tech Coloproctol 20:467-473

22. De Angelis N, Portigliotti L, Azoulay D, Brunetti F (2015) Transanal total mesorectal excision for rectal cancer: a single center experience and systematic review of the literature. Langenbeck's Arch Surg 400:945-959

23. Velthuis S, Nieuwenhuis DH, Ruijter TEG, Cuesta MA (2014) Transanal versus traditional laparoscopic total mesorectal excision for rectal carcinoma. Surg Endsc 28:3494-3499

24. Chen C, Lai Y, Jiang J, Chu C, Huang I (2016) Transanal total mesorectal excision versus laparoscopic surgery for rectal cancer receiving neoadjuvant chemoradiation: a matched case-control study. Ann Surg Oncol 23:1169-1176

25. Penna M, Hompes R, Arnold S, Wynn G, Austin R, Warusavitarne J, Moran B, Hanna GB, Mortensen NJ, Tekkis PP (2018) Incidence and risk factors for anastomotic failure in 1594 patients treated by transanal total mesorectal excision: results from the 
International TaTME Registry. Ann Surg https://doi.org/10.1097/ SLA.0000000000002653

26. Deijen CL, Tsai A, Koedam TW, Veltcamp Helbach M, Sietses C, Lacy AM, Bonjer HJ, Tuynman JB (2016) Clinical outcomes and case volume effect of transanal total mesorectal excision for rectal cancer: a systematic review. Tech Coloproctol 20:811-824

27. van Oostendorp SE, Koedam TWA, Sietses C, Bonjer HJ, Tuynman JB (2018) Transanal total mesorectal excision compared to laparoscopic TME for mid and low rectal cancer-current evidence. Ann Laparosc Endosc Surg. https://doi.org/10.21037/ ales.2018.04.02

28. Jayne D, Pigazzi A, Marshall H, Croft J, Corrigan N, Copeland J, Quirke P, West N, Rautio T, Thomassen N, Tilney H, Gudgeon M, Bianchi PP, Edlin R, Hulme C, Brown J (2017) Effect of roboticassisted vs conventional laparoscopic surgery on risk of conversion to open laparotomy among patients undergoing resection for rectal cancer. JAMA 318(16):1561-1569

29. Laurent C, Leblanc F, Gineste C, Saric J, Rullier E (2007) Laparoscopic approach in surgical treatment of rectal cancer. Br J Surg 94:1555-1561

30. Morino M, Parini U, Giraudo G, Salval M, Contul RB, Garrone C (2003) Laparoscopic total mesorectal excision: a consecutive series of 100 patients. Ann Surg 237:335-342

31. Hartley JE, Mehigan BJ, Qureshi AE, Duthie GS, Lee PW, Monson JR (2001) Total mesorectal excision: assessment of the laparoscopic approach. Dis Colon Rectum 44:315-321

32. Mizrahi I, Sands DR (2017) Transanal total mesorectal excision for rectal cancer: a review. Ann Laparosc Endosc Surg 2:144

33. Penna M, Hompes R, Arnold S, Wynn G, Austin R, Warusavitarne J, Moran B, Hanna GB, Mortensen NJ, Tekkis PP, TaTME Registry Collaborative (2016) Transanal total mesorectal excision international registry results of the first 720 cases. Laparosc Endosc Surg 266:111-117

34. Nagtegaal ID, Quirke P (2008) What is the role for the circumferential margin in the modern treatment of rectal cancer? J Clin Oncol 26:303-312

35. Battersby NJ, How P, Moran B, Stelzner S, West NP, Branagan G, Strassburg J, Quirke P, Tekkis P, Pedersen BG, Gudgeon M, Heald B, Brown G, MECURY II Study Group (2016) Prospective validation of a low rectal cancer magnetic resonance imaging staging system and development of a local recurrence risk stratification model: the MERCURY II study. Ann Surg 263:751-760

36. Park JS, Choi GS, Kim SH, Kim HR, Kim NK, Lee KY, Kang SB, Kim JY, Lee KY, Kim BC, Bae BN, Son GM, Lee SI, Kang H (2013) Multicenter analysis of risk factors for anastomotic leakage after laparoscopic rectal cancer excision. Ann Surg 257:665-671

37. Trencheva K, Morrissey KP, Wells M, Mancuso CA, Lee SW, Sonoda T, Michelassi F, Charlson ME, Milsom JW (2013) Identifying important predictors for anastomotic leak after colon and rectal resection: prospective study on 616 patients. Ann Surg 257:108-113

38. Borstlap WAA, Westerduin E, Aukema TS, Bemelman WA, Tanis PJ, Dutch Snapshot Research Group (2017) Anastomotic leakage and chronic presacral sinus formation after low anterior resection. Ann Surg, 266:870-877

39. Bertelsen CA, Andreasen AH, JÃ rgensen T, Harling H, Danish Colorectal Cancer Group (2010) Anastomotic leakage after anterior resection for rectal cancer: risk factors. Color Dis, 12:37-43

40. Paun BC, Cassie S, MacLean AR, Dixon E, Buie WD (2010) Postoperative complications following surgery for rectal cancer. Ann Surg 251:807-818

41. Chouillard E, Regnier ECA, Bonnet RVBV (2016) Transanal NOTES total mesorectal excision (TME) in patients with rectal cancer: is anatomy better preserved ? Tech Coloproctol 20:537-544

42. Fernández-Hevia M, Delgado S, Castells A, Tasende M, Momblan D, Diaz del G, Gobbo B, DeLacy J, Balust AM, Lacy (2015) Transanal total mesorectal excision in rectal cancer. Ann Surg 261:221-227

43. Perdawood SK, Al Khefagie GAA (2015) Transanal vs laparoscopic total mesorectal excision for rectal cancer: initial experience from Denmark. Colorectal Dis 18:51-58

44. Deijen CL, Velthuis S, Tsai A, Mavroveli S, de Lange-de ESM, Kler C, Sietses JB, Tuynman AM, Lacy GB, Hanna HJ, Bonjer (2016) COLOR III: a multicentre randomised clinical trial comparing transanal TME versus laparoscopic TME for mid and low rectal cancer. Surg Endosc 30:3210-3215 